\title{
The role of interleukin-17 during acute rejection after lung transplantation
}

\author{
B.M. Vanaudenaerde*, L.J. Dupont*, ${ }^{*}$, W.A. Wuyts*, E.K. Verbeken+, I. Meyts", \\ D.M. Bullens", E. Dilissen", L. Luyts*, D.E. Van Raemdonck" and G.M. Verleden*,
}

ABSTRACT: Acute rejection (AR) is an important complication that can occur after lung transplantation and constitutes a risk factor for bronchiolitis obliterans syndrome, which is characterised by a neutrophilic airway inflammation. The specific aim of this study was to investigate the role of interleukin (IL)-17, which promotes chemotaxis of neutrophils by inducing IL-8 production, in AR.

Cell differentials, mRNA and protein levels were quantified in bronchoalveolar lavages (BALs) taken from patients at $\mathbf{2 8}$ and $\mathbf{9 0}$ days after lung transplantation. The patient's rejection status was assessed by transbronchial biopsy.

An AR was found in nine out of the 26 patients examined, 28 days after transplantation. The number of BAL neutrophils and lymphocytes were increased in these patients. IL-17 mRNA and protein levels in the BAL were increased in patients with AR. Analysis of BAL obtained at day 90 after transplantation, demonstrated that the increase in IL-17 had disappeared, whereas the increase in neutrophils and lymphocytes persisted.

These data showed that interleukin-17 is temporarily upregulated in bronchoalveolar lavage during acute rejection. The number of lymphocytes and neutrophils are increased in bronchoalveolar lavage during acute rejection and may persist up to 2 months after acute rejection. These findings suggest that interleukin-17 is important in the pathophysiology of acute lung rejection.

KEYWORDS: Acute rejection, bronchoalveolar lavage, interleukin-17, interleukin-8, lung transplantation, neutrophils

ung transplantation (LTx) is a wellestablished treatment modality for patients with end-stage pulmonary disease [1]. A major complication in transplant patients is acute rejection (AR). Approximately $50-70 \%$ of $\mathrm{LTx}$ patients experience at least one episode of AR, which occurs most frequently during the first 3 months after an LTx [2]. The diagnosis of AR is based on clinical findings and/or histological confirmation by means of a transbronchial biopsy, the latter being characterised by an intra-graft perivascular and/or peribronchial infiltration of inflammatory cells. It has been shown that the frequency and the severity of AR episodes are associated with an increased risk of chronic rejection or bronchiolitis obliterans syndrome (BOS), which is the main obstacle for longterm success of an LTx [3].

In addition to transbronchial biopsies and lung function tests, analysis of bronchoalveolar lavage (BAL) provides another means of assessing inflammatory changes after an LTx. It is well known that lymphocytes are increased in the
BAL of patients with AR [4]. It is currently believed that AR is orchestrated by the helper (CD4+) subset of T-lymphocytes, which are activated by donor allopeptides. The cytokines produced by these activated T-cells, in turn stimulate the proliferation, chemotaxis and/or activation of cytotoxic (CD8+) T-lymphocytes, neutrophils and alveolar macrophages. These inflammatory cells contribute to graft injury [5]. Interleukin (IL)-17 is a specific T-lymphocytederived cytokine capable of inducing neutrophilic migration and activation both in vitro and in vivo [6], via the production of IL- 8 , the major neutrophilic chemoattractant cytokine. Both IL-8 and neutrophils have been identified as important triggers in the onset and progression of BOS [7].

The specific aim of the present study was to investigate the role of IL-17 in AR, which is an established risk factor for the development of BOS. IL-17 mRNA and protein, IL-8 mRNA and protein and a number of inflammatory cells were measured in the BAL samples taken from
AFFILIATIONS

*Laboratory of Pneumology and

\# Laboratory of Immunology,

Katholieke Universiteit,

'Lung Transplantation Unit and

${ }^{+}$Dept of Histopathology, University

Hospital Gasthuisberg, Leuven,

Belgium.

\section{CORRESPONDENCE}

G.M. Verleden

Dept Respiratory Disease and Lung

Transplantation Unit

University Hospital Gasthuisberg

Herestraat 49

B-3000 Leuven

Belgium

Fax: 3216346803

E-mail: geert.verleden@

uz.kuleuven.ac.be

\section{Received:}

February 192005

Accepted after revision:

December 122005

\section{SUPPORT STATEMENT}

G.M. Verleden is holder of the

GlaxoSmithKline chair for Respiratory

Pharmacology at the KULeuven,

Belgium. L.J. Dupont is a senior

research fellow of the "FWO

Vlaanderen". This project was funded

by FWO project nr G.0493.04. 
patients after an LTx during and after AR. The current authors compared these results between patients with AR and patients with no rejection at an identical time point after LTx. As it has been shown that the cell profile in AR varies depending on the post-operative time [8], the first evaluation was performed at $\sim 28$ days after an LTx. A follow-up evaluation was performed 3 months after the LTx.

\section{MATERIALS AND METHODS Patients and study protocol}

The LTx recipients grafted in University Hospital Gasthuisberg (Leuven, Belgium) between June 2002 and January 2004 were eligible for inclusion in this study. Immunosuppression was identical for all patients and included induction therapy with rabbit antithymocyte globulin (Fresenius, Schelle, Belgium) during 3-5 days, combined with a maintenance regimen of cyclosporin/tacrolimus, azathioprine/mycophenolate mofetil and methylprednisolone. All patients received acyclovir/ ganciclovir and cotrimoxazole prophylaxis. Exclusion criteria were: suture problems, infection or diffuse alveolar damage. Bronchial infection was excluded, based on clinical, radiological and/or transbronchial biopsy (TBB) findings. Colonisation per se was not an exclusion criterion. The Ethics Committee of the University Hospital Gasthuisberg approved the protocol.

\section{Forced expiratory volume in one second measurement}

The forced expiratory volume in one second (FEV1) was measured with the Masterscreen spirometer (Jaeger, Hoechberg, Germany). The best of three attempts, with a variability of $<10 \%$, was retained for analysis and results were expressed as percentage of predicted FEV1, according to the American Thoracic Society criteria [9].

\section{Transbronchial biopsies and bronchoalveolar lavage}

In addition to clinical (lung auscultation and chest radiographs) and functional (spirometry) evaluation, BAL and TBBs were performed in each patient at the time of discharge, $\sim 28$ days after the LTx surgery. For BAL, two aliquots of sterile $50 \mathrm{~mL}$ saline were instilled in the right middle lobe or the lingula. The returned fractions were pooled and used for several analyses including microbiology. A second fraction was used for differential cell count. A cytospin was made with $10^{5}$ cells $\cdot \mathrm{mL}^{-1}$ in a Shandon cytocentrifuge (Techgen, Zellik, Belgium). The cytospins were coloured with May-GrünwaldGiemsa. Differential cell counts were determined by counting at least 300 cells. Another fraction was immediately centrifuged at $500 \times g$ for $10 \mathrm{~min}$ at $4^{\circ} \mathrm{C}$. The cell pellet was lysed and used for quantitative PCR and the supernatant was used for protein measurement with ELISA. TBB specimens were examined for infections and for signs of $A R$, and were classified according to International Society for Heart \& Lung Transplantation (ISHLT) guidelines [10]. No routine TBB were taken at day 90 .

\section{IL-17 and IL-8 mRNA in bronchoalveolar lavage}

Total cellular RNA was isolated using a phenol-chloroform extraction and isopropanol precipitation as already described in previous studies [11]. For all the samples a constant amount of $1 \mu \mathrm{g}$ was reverse transcribed using a GeneAmp RNA PCR kit (Applied Biosystems, Lennik, Belgium). Real-time quantitative PCR amplification was performed for IL-17, IL- 8 and $\beta$-actin in duplicate with the ABI prism 7700 Sequence detector (Applied Biosystems) using a plasmid based internal calibration standard. Using a master mix protocol, each sample consisted of: $1 \mu \mathrm{g}$ cDNA, $0.4-\mu \mathrm{M}$ forward-reverse primer and probe, and $1 \times$ Universal Mastermix (Applied Biosystems). IL-17, IL-8 and $\beta$-actin cDNA were amplified in a thermal cycler (denaturation at $94^{\circ} \mathrm{C}$ for $15 \mathrm{~s}$ and annealing/extension at $60^{\circ} \mathrm{C}$ (IL-17 and IL8 ) or $67^{\circ} \mathrm{C}$ ( $\beta$-actin) for $60 \mathrm{~s}$ (45 cycli). Human IL-17, IL-8 and $\beta$ actin primers and probes were designed based on published sequences (table 1) and supplied by Eurogentec (Seraing, Belgium). All mRNA results were calculated as ratio of cytokine mRNA over $\beta$-actin mRNA. Individual levels of $\beta$ actin, which was used as a house-keeping gene, were not affected by the presence of rejection in the current study population.

\section{IL-17 and IL-8 protein in bronchoalveolar lavage}

IL-17 and IL-8 protein levels were analysed in $100 \mu \mathrm{l}$ of undiluted BAL, by means of a standard sandwich ELISA (Biosource SA, Nivelle, Belgium; sensitivity $=1$ and $2 \mathrm{pg} \cdot \mathrm{mL}^{-1}$, respectively). If the concentration was under the detection limit, a value of $1 \mathrm{pg} \cdot \mathrm{mL}^{-1}$ was accorded.

\section{Follow-up forced expiratory volume in one second, bronchoalveolar lavage cell count, IL-17 and IL-8}

Analysis of FEV1, BAL total and differential cell counts, IL-17 and IL- 8 was repeated on day 90, 2 months after the patients with AR had received anti-rejection therapy. The patients of the AR group were given $500 \mathrm{mg} \cdot \mathrm{day}^{-1}$ of methylprednisolone i.v. for 3 days (in case of a grade $\geqslant 2$ AR) or a two-fold increased dose of oral methylprednisolone with a taper over 2 weeks, to the initial dose in case of a grade $1 \mathrm{AR}$. The patients of the stable group received no additional immunosuppressive therapy.

TABLE 1 The primers and probes used

Primer

Probe
Forward

AATCTCCACCGCAATGAGGA

TGGCAGCCTTCCTGATTTCT

AGCCTCGCCTTTGCCGA
ACGTTCCCATCAGCGTTGA

TTAGCACTCCTTGGCAAAACTG CTGGTGCCTGGGGCG
FAM-CGGCACTTTGCCTCCCAGATCACA-TAMRA FAM-CAGCTCTGTGTGAAGGT-TAMRA FAM-CCGCCGCCCGTCCACACCCGCC-TAMRA

All sequences given as $5^{\prime}-3^{\prime}$. IL: interleukin 


\section{Statistical analysis}

All results are presented as median (interquartile range) and the Mann-Whitney U-test was used to test for significance. Correlations are calculated with the Spearman's rank test.

\section{RESULTS}

\section{Study population}

During the period of the study a total of 52 patients were transplanted; however, only 26 patients were included in the study protocol for various reasons, which all come down to the occurrence of accompanying problems such as: no BAL performed at one of the two time-points $(n=5)$; gross infection, needing therapy around or between the time-points of a sampling moment $(n=5)$; early post-operative death $(n=3)$, acute, symptomatic rejection between time-point 1 and 2 $(\mathrm{n}=2)$; diffuse alveolar damage on transbronchial biopsies $(n=3)$; presence of tumour in explanted or implanted lung $(n=2)$; very young age $(<10 \mathrm{yrs}, \mathrm{n}=1)$; persistent low FEV1 without obvious explanation $(n=3)$; cerebral bleeding and no cooperation $(\mathrm{n}=1)$; and azithromycin started as antiinflammatory agent early post-operatively $(n=1)$

Table 2 summarises the characteristics of the patients included in the present study, together with the characteristics of the AR and control group. All tests were performed during a period of 2 days before planned discharge at a median post-transplant time of 28 (20-31) days. At that time, all patients were clinically stable as defined by normal lung auscultation, absence of fever, normal oxygen saturation (without supplemental oxygen) and a normal chest radiograph. Nevertheless, nine of these 26 clinically stable patients showed signs of AR after a pathological examination. Two patients had an AR grade A1 and seven patients $\geqslant A 2$ grade. The remaining 19 patients were found to have an A0 score on TBB. A B-score could not be accurately determined in two patients of the control group and one patient in the AR group, due to inadequate biopsy samples. Only two of the nine patients with an A-score $>0$ on TBB also had B1 score, while the remaining six patients of the AR group had a score of $\mathrm{B} 0$. All other patients with a score of A0 on TBB were diagnosed as B0. The maintenance immunosuppressive therapy of both groups is also reported in table 2. At day 90, TBBs were not routinely performed and retrospective functional (spirometry) analysis and clinical (lung auscultation and chest radiograph) evaluations were used to confirm the stable status of the patients in both groups. Nevertheless, TBB was performed in nine patients (seven of the control group and two of the AR group) for confirmation of the absence of AR at day 90.

Colonised samples were not excluded if there was no clinical (e.g. fever), biochemical (increase in C-reactive protein) and radiological evidence for infection or evidence of bacteria or fungi in the biopsy. At day 28, colonisation of Pseudomonas aeruginosa or Candida albicans or Stenotrophomonas maltophilia was present in three samples. The first two were in the control group and the third was from the AR group. At day 90, 11 samples demonstrated colonisation without clinical, biochemical or radiological signs of infection. A total of six positive cultures were found in the control group at day 90: Penicillium $\mathrm{sp} .(\mathrm{n}=2)$, Aspergillus niger $(\mathrm{n}=1)$, S. maltophilia $(\mathrm{n}=1)$, S. aureus $(\mathrm{n}=1)$ and $P$. aeruginosa $(\mathrm{n}=1)$. Five out of nine follow-up samples, taken from the AR group, were colonised with

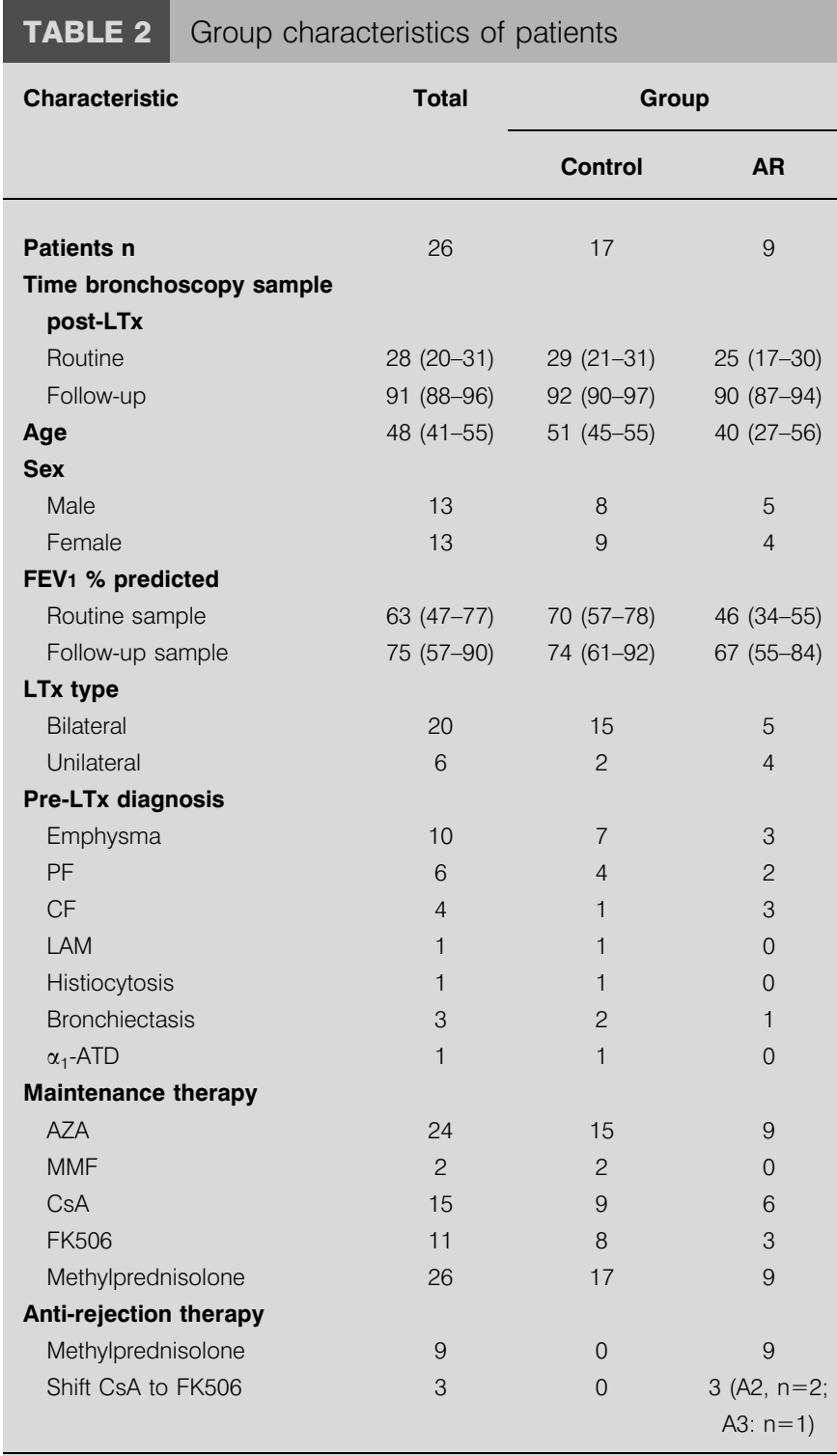

Data are presented as median (interquartile range) or $\mathrm{n}$, unless otherwise stated. AR: acute rejection; LTx: lung transplantation; FEV1: forced expiratory volume in one second; PF: pulmonary fibrosis; CF: cystic fibrosis; LAM: lymfangioleiomyomatosis: $\alpha_{1}$-ATD: $\alpha_{1}$-antitrypsin deficiency; AZA: azathioprine; MMF: mycophenolate mofetil; CsA: cyclosporin A; FK506: tacrolimus.

$P$. aeruginosa $(\mathrm{n}=2), C$. albicans $(\mathrm{n}=1)$, Coagulase-negative staphylococcus $(n=1)$ and one sample had both $P$. aeruginosa and $C$. albicans.

\section{Forced expiratory volume in one second}

Patients in the AR group had a significantly lower FEV1 (\% pred) than compared with patients in the control group $(p=0.0047)$ at day 28. There was a significant increase in FEV1 at day 90 in the patients with AR compared with the FEV1 at day $28(p=0.038)$. There was no more significant difference between the FEV1 of both groups at day $90(p=0.32$, table 3$)$.

Total and differential cell count in bronchoalveolar lavage The total cell count in BAL at day 28 did not differ between the AR group and control group $(p=0.69)$. There was a significant 


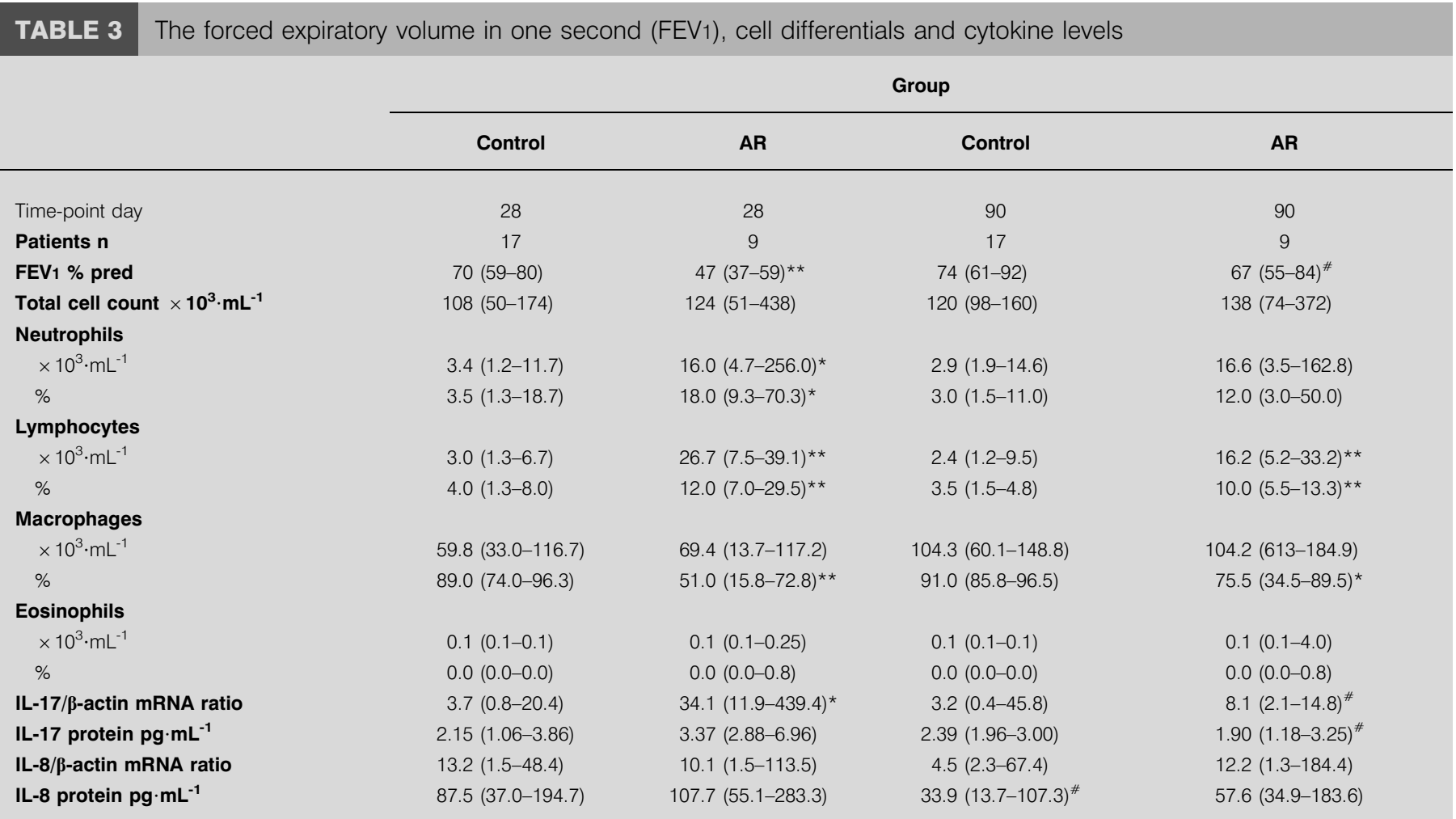

Data are presented as median (interquartile range), unless otherwise stated. AR: acute rejection; IL: interleukin. *: $\mathrm{p}<0.05$ for AR group versus stable group; ${ }^{\star \star}$ : $\mathrm{p}<0.01$ for AR group versus stable group; ${ }^{*}: \mathrm{p}<0.05$ for day 28 versus day 90.

increase in the total number, as well as percentage of neutrophils $(\mathrm{p}=0.031$ and $\mathrm{p}=0.022$, respectively) and lymphocytes ( $p=0.0036$ and $p=0.0051$, respectively) in the AR group versus the control group. Macrophages did not differ in the total number of cells $(\mathrm{p}=0.48)$, but the percentage was significantly decreased in AR $(p=0.0020)$, as a result of compensation for the increase in neutrophils and lymphocytes. Eosinophil levels (both percentage and total) were low and invariable (table 3 and fig. 1a and b).

A correlation was found between BAL lymphocytes and the grade of $A R(r=0.57, p=0.0022, n=26)$. There was also a weak correlation between BAL neutrophils and the grade of AR $(\mathrm{r}=0.45, \mathrm{p}=0.020, \mathrm{n}=26)$.

The total cell count in BAL at day 90 was not different when compared to the cell count at day 28. The high level of BAL lymphocytes in patients with AR at day 28 did not decrease $(p=0.67)$, when measured at day 90. There was still a significant difference in the number of BAL lymphocytes between the AR and the control group at day 90 ( $p=0.0060$, fig 1c). BAL neutrophils in patients with AR did not decrease when measured at day 90, after anti-rejection therapy $(p=0.93)$. The difference in BAL neutrophils between the AR and control group at day 90 was no longer significant $(p=0.11$, fig. $1 \mathrm{~d}$ and table 3).

Neither at day 29 nor at day 90 was there a significant difference in BAL neutrophilia between colonised and noncolonised patients.

\section{IL-17 mRNA and protein in bronchoalveolar lavage}

IL-17 mRNA in BAL was increased in patients with AR $(p=0.024)$ compared with the control patients. There was also an obvious trend towards a higher IL-17 protein level $(p=0.059$, table 3$)$ in the AR group.

IL-17 (mRNA and protein) levels correlated with the grade of AR $(\mathrm{r}=0.53, \mathrm{p}=0.0056, \mathrm{n}=26$ and $\mathrm{r}=0.49, \mathrm{p}=0.011, \mathrm{n}=26$, respectively; fig 2). No correlation was found between IL-17 mRNA and the number of lymphocytes in BALF $(r=0.13$, $\mathrm{p}=0.48, \mathrm{n}=26$ ). IL-17 protein, on the other hand, correlated with lymphocytes in BAL $(r=0.49, \mathrm{p}=0.011, \mathrm{n}=26$; fig 3$)$. After IL-17 mRNA levels were corrected for (multiplied with) the number of lymphocytes, which are considered as the main source of IL-17 production, the current authors could demonstrate a significant correlation between the protein levels of IL-17 and the corrected mRNA levels of IL-17 $(\mathrm{r}=0.71, \mathrm{p}=0.0001, \mathrm{n}=26$; fig 4$)$.

IL-17 (mRNA and protein) in patients with AR at day 90 was significantly lower than IL-17 levels at day $28(\mathrm{p}=0.032$ and $p=0.032$, respectively). There was no difference in the IL-17 levels at day 90 between the patients of the AR and control group $(\mathrm{p}=0.67$, table 2$)$.

\section{IL-8 mRNA and protein in bronchoalveolar lavage}

The mRNA (ratio of cytokine mRNA level over $\beta$-actin mRNA) and protein levels of IL- 8 in BAL are shown in table 3 . IL- 8 mRNA was not different between the AR and the control group (day 28 and day 90, p=0.89 and 0.67, respectively). IL-8 

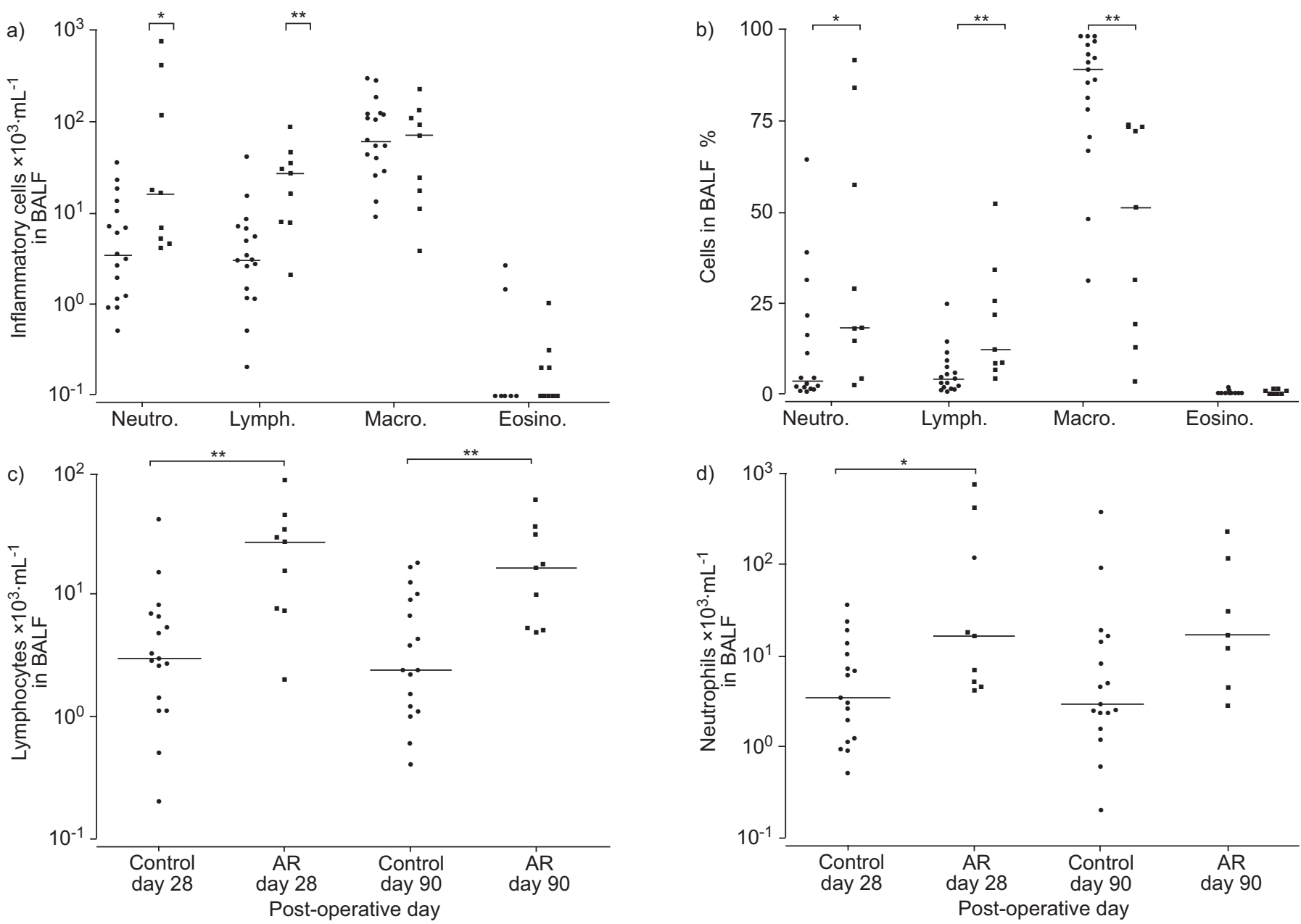

FIGURE 1. The cellular profile of the bronchoalveolar lavage (BAL) samples in the control

; $\mathrm{n}=17)$ and acute rejection (AR,

$\mathrm{n}=9$ ) groups. a) Total counts of inflammatory cells in the BAL fluid (BALF) at day 28. b) Percentage of inflammatory cells in the BALF at day 28. c) Lymphocyte numbers of both the control and AR groups at days 28 and 90 . d) Neutrophil numbers of both the control and AR groups at days 28 and 90. Neut.: neutrophil; Lymph.: Iymphocytes; Macro.: macrophages; Eosino.: eosinophils. *: $p<0.05 ;{ }^{*}: p<0.01$.

protein $\left(\mathrm{pg} \cdot \mathrm{mL}^{-1}\right)$ levels did not differ between $\mathrm{AR}$ and control groups at day $28(p=0.31)$ and at day $90(p=0.28$, table 3$)$. IL-8 protein levels decreased in both groups at day 90 , although this decrease was not statistically significant (table 3).

Correlation analysis with the number of neutrophils in BAL showed no correlation for IL-8 mRNA $(r=0.25, p=0.22, n=26$; fig. 5). IL-8 protein was found to correlate with the number of neutrophils in BAL $(r=0.64, p=0.0004, n=26$; fig. 5). IL-8 (both mRNA and protein) in BAL did not correlate with the grade of AR $(r=0.015, p=0.94, n=26$ and $r=0.13, p=0.51, n=26$, respectively).

IL-8 (mRNA and protein) levels in BAL at day 90 were not different compared with levels at day 28 for both groups (table 3).

\section{DISCUSSION}

In the current study the present authors have demonstrated, for the first time that both IL-17 mRNA and protein are upregulated in the BAL of LTx patients with acute allograft rejection. IL-17 correlated with the severity of AR. In agreement with data from other authors, the present authors also found an increase in BAL lymphocytes $[4,12]$ and neutrophils [8] in AR. This increase in BAL lymphocytes and neutrophils, in patients with an AR episode at day 28, did not normalise when analysed at a 2-month follow-up examination. IL-8, total cell count, macrophages and eosinophils did not change during AR.

A critical step in order to study a homogenous group of LTx patients is the selection of patients and samples. An important consideration is the cell profile variation by time as demonstrated by TIKKANEN et al. [8]. The use of a fixed time-point for evaluation ( $\sim 28$ days after LTx) allows statistically adequate comparison between patients with rejection and patients without rejection. In the current study the authors complied with this prerequisite by evaluating the patients in both the AR group and the control group at two identical time-points $(\sim 28$ and 90 days after LTx). The patient characteristic profile was not different between the AR group and the control group, allowing statistically adequate comparison between both groups. 

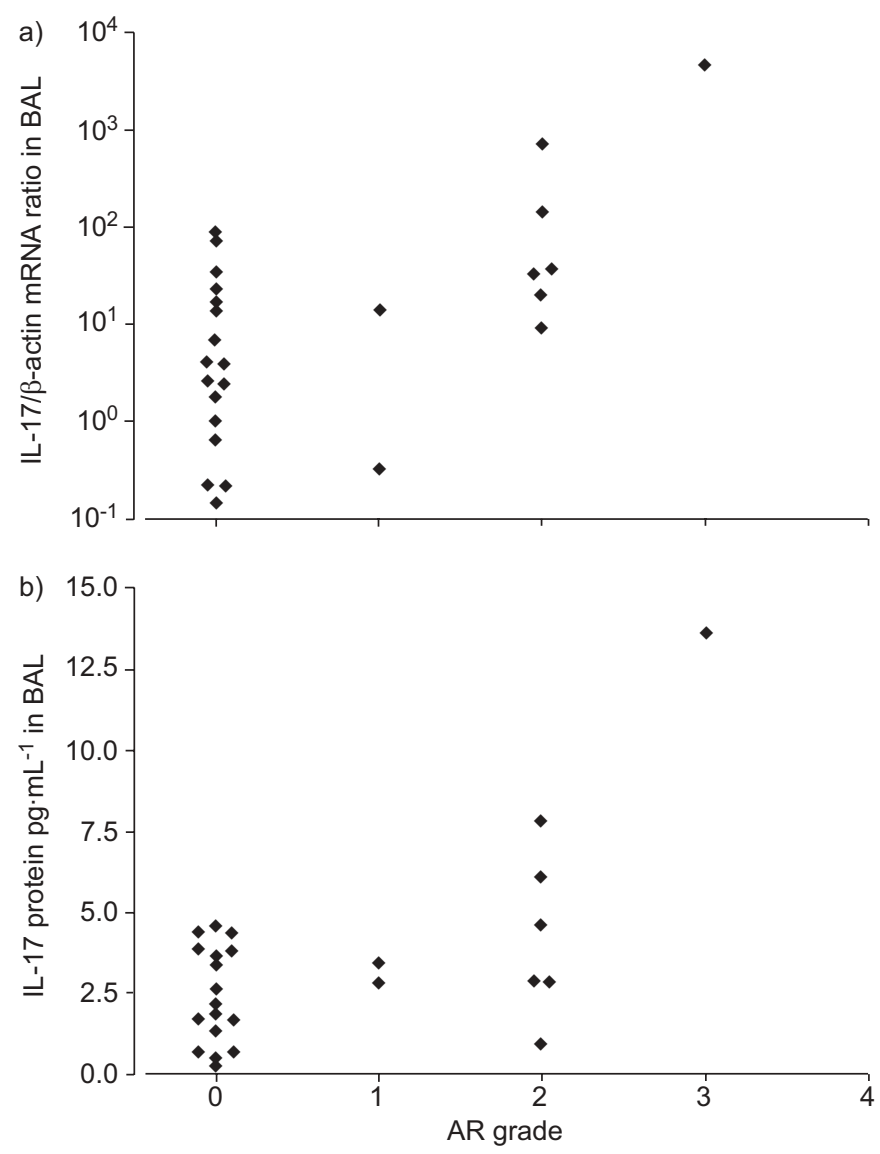

FIGURE 2. Interleukin (IL)-17 mRNA and protein levels measured in bronchoalveolar lavage (BAL) $\sim 28$ days after lung transplantation using $\mathrm{PPCR}$ and ELISA. The mRNA levels are expressed as a ratio of IL-17 over $\beta$-actin and the protein levels are expressed $\mathrm{pg} \cdot \mathrm{mL}^{-1}$. Correlation between a) IL-17 mRNA and the grade of acute rejection (AR; $r=0.53, p=0.0056, n=26$ ) and $b$ ) IL-17 protein and the grade of $A R(r=0.42, p=0.0032, n=26)$.

Using transbronchial biopsy as a surveillance procedure, silent AR was detected in $35 \%$ of clinically and functionally stable transplant patients; $27 \%$ had a $\geqslant \mathrm{A} 2$ grade. The frequency of silent AR in the present study population was in agreement with previous reports [13-15]. Early detection of the occurrence of rejection may decrease the possibility of the graft being more severely injured. Taking these observations into account, the current data actually underscore the potential importance of surveillance bronchoscopy in the early posttransplant period.

In the present study, BAL lymphocytes were increased in AR and correlated with the severity of AR as described previously [16]. The current authors also found BAL neutrophils to be increased and to correlate with the grade of AR. This increase was also demonstrated in several other studies, although not consistently [8, 17, 18]. These papers clearly illustrate that neutrophils may be present in BAL during AR. In the study by SLEBOS et al. [12], although the median BAL neutrophil percentages during AR were only 3 and $1.5 \%$, respectively, in the bronchial and the alveolar fraction, the numbers increased to 89 and $26 \%$, respectively. Also, in the study by REYNAUD-GAUBERT et al. [17], during AR, the mean neutrophil
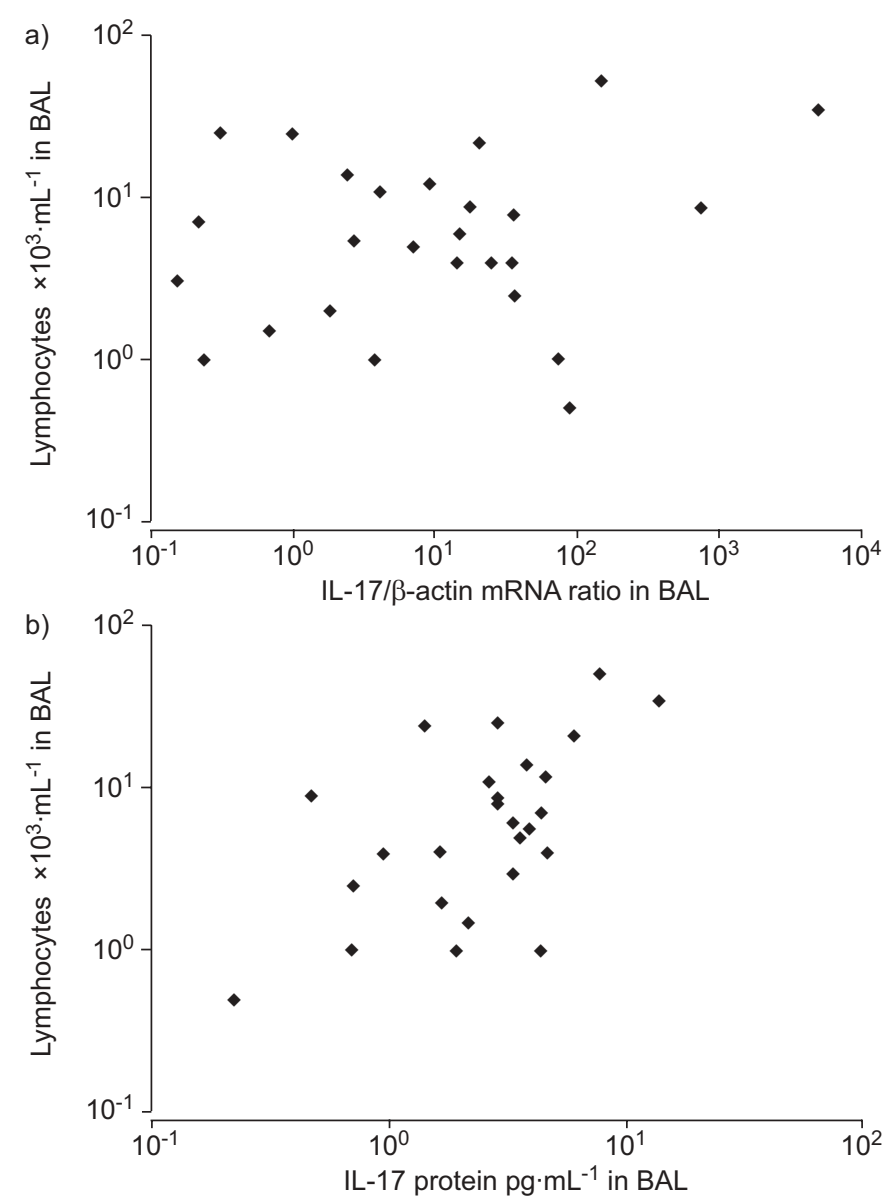

FIGURE 3. Interleukin (IL)-17 mRNA and protein levels measured in bronchoalveolar lavage (BAL) 28 days after lung transplantation. The mRNA levels are expressed as a ratio of $\mathrm{IL}-17$ over $\beta$-actin and the protein levels are expressed in $\mathrm{pg} \cdot \mathrm{mL}^{-1}$. Correlation between a) IL-17 mRNA and lymphocytes $(r=0.13, p=0.54$, $\mathrm{n}=26)$ and $\mathrm{b}) \mathrm{IL}-17$ protein and lymphocytes $(\mathrm{r}=0.49, \mathrm{p}=0.011, \mathrm{n}=26)$.

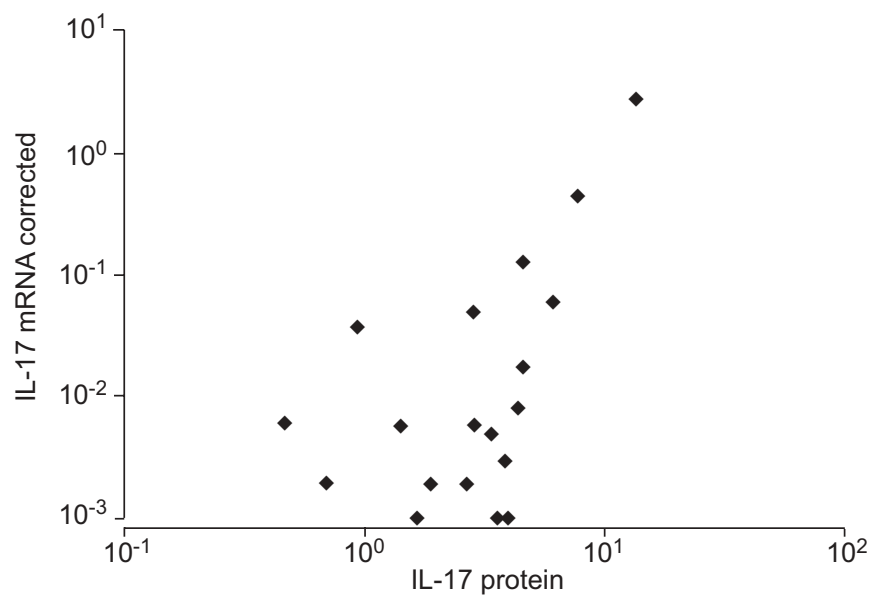

FIGURE 4. mRNA and protein levels measured in bronchoalveolar lavage (BAL) $\sim 28$ days after lung transplantation. The mRNA levels are expressed as a ratio of interleukin (IL)-17 over $\beta$-actin and the protein levels are expressed in $\mathrm{pg} \cdot \mathrm{mL}^{-1}$. The $\mathrm{mRNA}$ levels for $\mathrm{IL}-17$ are corrected for total lymphocytes. Correlation between mRNA (corrected) and protein $(r=0.71, p<0.0001, n=26)$. 

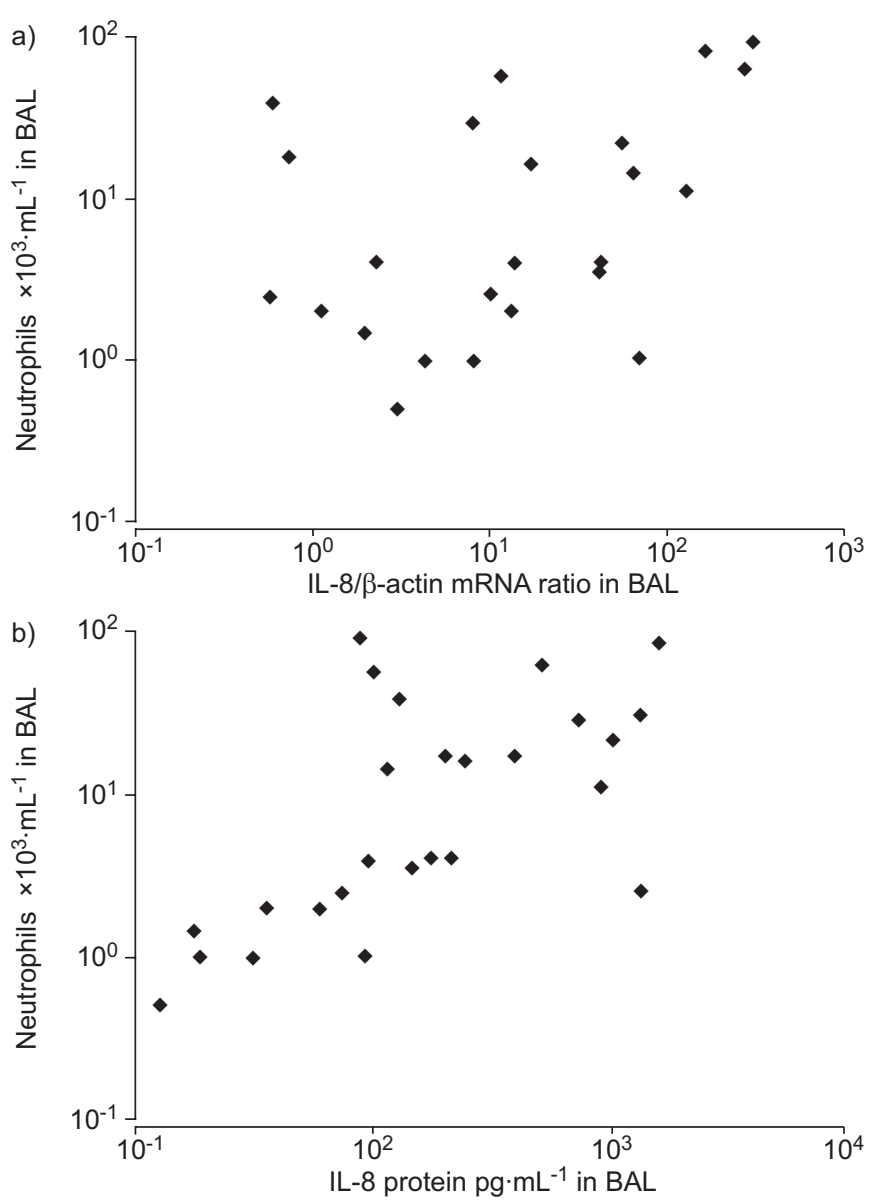

FIGURE 5. Interleukin (IL)-8 mRNA and protein levels measured in bronchoalveolar lavage $(B A L) \sim 28$ days after lung transplantation. The mRNA levels are expressed as a ratio of IL-8 over $\beta$-actin and the protein levels are expressed in $\mathrm{pg} \cdot \mathrm{mL}^{-1}$. Correlation between a) $\mathrm{IL}-8 \mathrm{mRNA}$ and neutrophils $(r=0.25, p=0.22$, $\mathrm{n}=26)$ and $\mathrm{b}) \mathrm{IL}-8$ protein and neutrophils $(\mathrm{r}=0.64, \mathrm{p}=0.0004, \mathrm{n}=26)$.

percentage in BAL was $12.3 \%$. These studies clearly indicate, as does the present study, that neutrophils may play a role in AR. These varying percentages may be due to the degree of AR, which is not always clearly stated and may, in part, be explained by the method used to perform the BAL. In fact when BAL is performed with only two fractions (50$60 \mathrm{~mL} \cdot$ fraction $^{-1}$ ) and when the fractions are pooled (as in the current study, not throwing away the first fraction), the neutrophil percentage tends to be higher, as is very well documented by MARTIN et al. [19] and SLEBOS et al. [12]. The suggestion that colonisation could be involved in the increased BAL neutrophilia can be eliminated by the presence of only one colonised sample in the AR group (see Study population section). Moreover, neither at day 28 nor at day 90 was there a significant difference in BAL neutrophilia between colonised and noncolonised patients.

In the pathophysiology of AR, after organ transplantation, lymphocytes are regarded as the main culprits, whereas the potential role of the neutrophils in AR is hardly mentioned [8, 17, 18]. Perhaps the idea that $A R$ is characterised by a lymphocytic influx and chronic rejection by a neutrophilic influx should be revised. It is possible that both acute and chronic rejection represent a continuum of inflammatory events, starting with macrophage activation, followed by early lymphocyte activation and neutrophil migration. In lung transplant patients who developed chronic rejection it has already been shown that an increase of lymphocytes is a predisposition to the development of BOS [20]. However, histopathologically, AR is characterised by a temporary perivascular- and bronchiolar-leukocyte infiltration, whereas BOS is characterised by a persistent airway neutrophilia leading to airway fibrosis and obliteration $[1,21]$.

Quantitative PCR is a useful tool in the research of cytokine expression in LTx, as it enables mRNA expression, specifically produced by the inflammatory cells present in BAL (e.g. IL-17) to be measured. Alternatively, ELISA measures the protein concentration produced by all cells (inflammatory and structural cells) that are secreted into the airway lumen (e.g. IL-8). A potential methodological criticism is the use of $\beta$-actin as a house-keeping gene and the notion that the expression might be affected by different immunosuppressive therapies $[22,23]$. As a result and prior to the current study analysis, the present authors have shown that $\beta$-actin mRNA expression in BAL of patients after LTx was not altered by the presence of an AR.

Until now it was not clear if IL-17, which is mainly produced by T-helper (Th)0/Th1-lymphocytes [24], was involved in AR after LTx. In human and experimental renal allograft studies, IL-17 is involved in the early events of AR [25]. LOONG et al. [25] demonstrated an increase of human IL-17 in subclinical (borderline) rejection of renal allograft biopsies and none in urinary tract infection and renal graft recipients with normal graft function. The involvement of IL-17 in acute vascular rejection was demonstrated indirectly, by using an IL-17R:Fc fusion protein to inhibit the IL-17 action [26]. IL-17 may be important in the pathophysiology of AR due to two remarkable features of this pro-inflammatory cytokine. First, IL-17 is specifically produced by T-lymphocytes [6], which are key players in the onset of AR. Secondly, the current authors recently provided in vitro evidence that IL-17 is capable of inducing IL-8 production (the major neutrophilic chemoattractant) in human airway smooth muscle cells [27] identified by DiGiovine et al. [21], as the predominant place where IL-8 is produced in patients with BOS. It has already been demonstrated, both in vitro and in vivo, that IL-17 is capable of inducing neutrophilic migration and activation, probably through the release of IL-8 [28, 29]. Any mediator, e.g. IL-17, specifically produced by lymphocytes and capable of inducing an increase in neutrophils, whether directly or indirectly through IL-8, may exert a significant role in the pathogenesis of AR. The absence of an increased IL- 8 expression (increase in $\mathrm{AR}$ and correlation with IL-17) in the present study is surprising and may suggest that the IL-17 mediated attraction of neutrophils in AR involves other mechanisms, which remain speculative at the moment.

A correlation was found between IL-17 protein and BAL lymphocytes, since there is no evidence that structural airway cells produce IL-17, again indicating that mainly lymphocytes produce IL-17. IL-17 mRNA and lymphocytes did not correlate. This is probably due to IL-17 mRNA expression, 
relating more to the activation status of the lymphocytes than to the actual number of lymphocytes. After correction of the IL17 mRNA for the number of lymphocytes, the present authors found an obvious correlation between IL-17 mRNA and IL-17 protein in BAL. Recent evidence has indicated that neutrophils may also be involved in the production of IL-17 [30]. Further in situ hybridisation or cytometric intracytoplasmatic staining and localisation for IL-17 should be able to resolve this matter.

In the absence of clinical and radiological signs, TBB was the only indicator for AR at day 28. At day 90 TBB was not routinely performed, which might be a shortcoming in the present study. However, the significant improvement of the low FEV1 values in the AR group may suggest the resolution of the AR at day 90, since in the control group the FEV1 did not significantly change between 1 and 3 months. As a consequence, the current authors could not pathologically prove the resolution of the AR at day 90, but based on the present results and the functional evolution of the patients, it was assumed that the AR may be resolved. The increase in the airway inflammation of lymphocytes and neutrophils in patients with AR at day 28 persisted (at least) until day 90. The exact significance of this persisting inflammation is not known at the present time and may lead to speculations to alter antirejection therapy, which is far beyond the scope of the present study. However, the current results are in agreement with previous studies looking at serial determinations of BAL cell profile. CLELLAND and co-workers [18, 31] found that the perivascular and peribronchiolar infiltration of lymphocytes and neutrophils did not entirely disappear 21 or 24 days after anti-rejection therapy. Although the airway infiltrates displayed many similarities to the perivascular infiltrates, CLELLAND et al. [31] observed a slower resolution after treatment of airway infiltrates than of perivascular infiltrates, which agrees with the current findings of persistently elevated lymphocyte and neutrophil numbers 2 months after antirejection therapy. These authors attributed the apparent persistence of the inflammatory cells to a reduced blood perfusion of the airway mucosa, as seen experimentally in AR [32], and which limits the access of steroids to the airway infiltrate. In the present study, IL-17 mRNA and protein in patients with AR on day 28, returned to levels comparable with the control group when measured at day 90 after transplantation. Whether this reduction of IL-17 expression may be attributed to the anti-rejection therapy alone or represents a spontaneous evolution remains speculative.

In conclusion, the current authors have convincingly demonstrated that in addition to an increase in lymphocytes and neutrophils, interleukin-17 is upregulated in the bronchoalveolar lavage during acute lung allograft rejection and correlates with the grade of acute rejection. The present authors hypothesise that interleukin-17 may be important in acute rejection and features as a signal between the lymphocytes and neutrophils. Interleukin-17 may play a major role in the development of acute rejection and merits further attention as to its role in the development of obliterative bronchiolitis / bronchiolitis obliterans syndrome. The significance of persistent airway neutrophilia after an acute rejection remains to be further elaborated.

\section{REFERENCES}

1 Verleden GM. Chronic allograft rejection (obliterative bronchiolitis). Sem Respir Crit Care Med 2001; 22: 551-557.

2 Trulock EP, Edwards LB, Taylor DO, et al. The Registry of the International Society for Heart and Lung Transplantation: Twentieth official adult lung and heartlung transplant report - 2003. J Heart Lung Transplant 2003; 22: 625-635.

3 Boehler A, Kesten S, Weder W, Speich R. Bronchiolitis obliterans after lung transplantation: a review. Chest 1998; 114: 1411-1426.

4 Laan M, Linden A, Riise GC. IL-16 in the airways of lung allograft recipients with acute rejection or obliterative bronchiolitis. Clin Exp Immunol 2003; 133: 290-296.

5 Watschinger B. How T-cells recognize alloantigenevidence for 2 pathways of allorecognition. Nephrol Dial Transplant 1995; 10: 1556-1558.

6 Linden A, Laan M, Anderson GP. Neutrophils, interleukin17A and lung disease. Eur Respir J 2005; 25: 159-172.

7 Reynaud-Gaubert M, Marin V, Thirion X, et al. Upregulation of chemokines in bronchoalveolar lavage fluid as a predictive marker of post-transplant airway obliteration. J Heart Lung Transplant 2002; 21: 721-730.

8 Tikkanen J, Lemstrom K, Halme M, Pakkala S, Taskinen E, Koskinen P. Cytological monitoring of peripheral blood, bronchoalveolar lavage fluid, and transbronchial biopsy specimens during acute rejection and cytomegalovirus infection in lung and heart-lung allograft recipients. Clin Transplant 2001; 15: 77-88.

9 Anon. Standardization of spirometry - 1987 update. Am Rev Respir Dis 1987; 136: 1285-1298.

10 Yousem SA, Berry GJ, Cagle PT, et al. Revision of the 1990 working formulation for the classification of pulmonary allograft rejection: lung rejection study group. J Heart Lung Transplant 1996; 15: 1-15.

11 Wuyts WA, Vanaudenaerde BM, Dupont LJ, Demedts MG, Verleden GM. N-acetylcysteine reduces chemokine release via inhibition of p38 MAPK in human airway smooth muscle cells. Eur Respir J 2003; 22: 43-49.

12 Slebos D, Postma DS, Koeter GH, van der Bij W, Boezen M, Kauffman HF. Bronchoalveolar lavage fluid characteristics in acute and chronic lung transplant rejection. J Heart Lung Transplant 2004; 23: 532-540.

13 Hosenpud JD, Bennett LE, Keck BM, Fiol B, Novick RJ. The Registry of the International Society for Heart and Lung Transplantation: Fourteenth Official Report - 1997. J Heart Lung Transplant 1997; 16: 691-712.

14 Trulock EP, Ettinger NA, Brunt EM, Pasque MK, Kaiser LR, Cooper JD. The role of transbronchial lung-biopsy in the treatment of lung-transplant recipients - An analysis of 200 consecutive procedures. Chest 1992; 102: 1049-1054.

15 Boehler A, Vogt P, Zollinger A, Weder W, Speich R. Prospective study of the value of transbronchial lung biopsy after lung transplantation. Eur Respir J 1996; 9: 658-662.

16 De Hoyos A, Chamberlain D, Schvartzman R, et al. Prospective assessment of a standardized pathologic grading system for acute rejection in lung transplantation. Chest 1993; 103: 1813-1818.

17 Reynaud-Gaubert M, Thomas P, Gregoire R, et al. Clinical utility of bronchoalveolar lavage cell phenotype analyses 
in the postoperative monitoring of lung transplant recipients. Eur J Cardiothorac Surg 2002; 21: 60-66.

18 Clelland C, Higenbottam $\mathrm{T}$, Stewart $\mathrm{S}$, et al. Bronchoalveolar lavage and transbronchial lung biopsy during acute rejection and infection in heart-lung transplant patients. Studies of cell counts, lymphocyte phenotypes, and expression of HLA-DR and interleukin-2 receptor. Am Rev Respir Dis 1993; 147: 1386-1392.

19 Martin TR, Raghu G, Maunder RJ, Springmeyer SC. The effects of chronic bronchitis and chronic air-flow obstruction on lung cell populations recovered by bronchoalveolar lavage. Am Rev Respir Dis 1985; 132: 254-260.

20 Whitford HM, Orsida B, Pais M, et al. Features of bronchoalveolar lavage (BAL) in lung transplant recipients (LTR) who later develop bronchiolitis obliterans syndrome (BOS). J Heart Lung Transplant 2001; 20: 176.

21 DiGiovine B, Lynch JP 3rd, Martinez FJ, et al. Bronchoalveolar lavage neutrophilia is associated with obliterative bronchiolitis after lung transplantation: role of IL-8. J Immunol 1996; 157: 4194-4202.

22 Gibbs PJ, Cameron C, Tan LC, Sadek SA, Howell WM. House keeping genes and expression analysis in transplant reciepients: a note of caution. Transpl Immunol 2003; 12: 89-97.

23 Miyamoto S, Safer B. Immunosuppressants FK506 and rapamycin have different effects on the biosynthesis of cytoplasmic actin during the early period of $\mathrm{T}$ cell activation. Biochem J 1999; 344: 803-812.

24 Aarvak T, Chabaud M, Miossec P, Natvig JB. IL-17 is produced by some proinflammatory Th1/Th0 cells but not by Th2 cells. J Immunol 1999; 162: 1246-1251.

25 Loong CC, Hsieh HG, Liu WY, Chen A, Lin CY. Evidence for the early involvement of interleukin 17 in human and experimental renal allograft rejection. I Pathol 2002; 197: 322-332.

26 Tang JL, Subbotin VM, Antonysamy MA, Troutt AB, Rao AS, Thomson AW. Interleukin-17 antagonism inhibits acute but not chronic vascular rejection. Transplantation 2001; 72: 348-350.

27 Vanaudenaerde BM, Wuyts WA, Dupont LJ, Van Raemdonck DE, Demedts MM, Verleden GM. Interleukin-17 stimulates release of interleukin-8 by human airway smooth muscle cells in vitro: a potential role for interleukin-17 and airway smooth muscle cells in bronchiolitis obliterans syndrome. J Heart Lung Transplant 2003; 22: 1280-1283.

28 Hoshino H, Lotvall J, Skoogh BE, Linden A. Neutrophil recruitment by interleukin-17 into rat airways in vivo. Role of tachykinins. Am J Respir Crit Care Med 1999; 159: 1423-1428.

29 Linden A, Hoshino H, Laan M. Airway neutrophils and interleukin-17. Eur Respir J 2000; 15: 973-977.

30 Ferretti S, Bonneau O, Dubois GR, Jones CE, Trifilieff A. IL17 , produced by lymphocytes and neutrophils, is necessary for lipopolysaccharide-induced airway neutrophilia: IL-15 as a possible trigger. J Immunol 2003; 170: 2106-2112.

31 Clelland CA, Higenbottam TW, Stewart S, Scott JP, Wallwork J. The histological changes in transbronchial biopsy after treatment of acute lung rejection in heart-lung transplants. J Pathol 1990; 161: 105-112.

32 Tanabe H, Yada I, Namikawa S, Kusagawa M. Early detection of lung rejection by measurement of bronchial mucosal blood-flow using laser doppler flowmeter. Transplant Proc 1989; 21: 2590-2591. 